\title{
Individualist, Collectivist and Gender Moderated Differences toward Online Purchase Intentions in Jordan
}

\author{
Shadi Ahmed Kahttab ${ }^{1}$, Excimirey Amer Al-Manasra², Mohammed Khair Saleem Abu Zaid ${ }^{2}$ \& Fadi Taher \\ Qutaishat $^{1}$ \\ ${ }^{1}$ Department of Management Information Systems, Al-Balqa’ Applied Univesity, Al-Salt, Jordan \\ ${ }^{2}$ Department of Management \& Marketing, Al-Balqa’ Applied Univesity, Al-Salt, Jordan \\ Correspondence: Shadi Ahmed Kahttab, Department of Managament Information Systems, Al-Balqa' Applied \\ Univesity, Al-Salt, Jordan. Tel: 962-79-619-8129. E-mail: shadikhattab@hotmail.com
}

Received: March 20, 2012

Accepted: April 26, $2012 \quad$ Online Published: July 1, 2012

doi:10.5539/ibr.v5n8p85

URL: http://dx.doi.org/10.5539/ibr.v5n8p85

\begin{abstract}
The purpose of this paper is to explore individualist and collectivist gender moderated differences toward online purchase intentions. Data were collected via questionnaires from 241 student in Al-Balqa' Applied University in Jordan. The collected data were analyzed using descriptive statistics. In addition, factor and cluster analysis were used to group the sample according to individualistic and collectivistic cultural factors. Two-way ANOVA test was used to test the study hypotheses. The results of this study depicted that there was a significant difference between male and female toward online purchase intentions. The study also depicted that, there was a significant difference in the intention to purchase online according to individualist, mixed and collectivist cultural factors. Furthermore, the two-way interaction between gender and individualist, mixed and collectivist groups was significant regarding intention to purchase online.
\end{abstract}

Keywords: individualism, collectivism, gender, online purchase intention

\section{Introduction}

\subsection{The Context and Problem of This Research}

Internet users nowadays, with various experiences, are considering the Internet technology to be the greatest new opportunity for trading in this century. What was formerly called information revolution is now called the Internet and e-commerce revolution (Henari \& Mahboob, 2008).

The social and cultural aspects for many nations are considered to be major obstacles to the spread of e-commerce. Many studies have shown that the main reasons behind the delays in the wide spread of e-commerce in many countries are due to social and cultural reasons (Gong, 2009). E-commerce is being considered as a major indicator and support for the economic development and prosperity in the developed countries (Javalgi et al., 2005). Taking into consideration the escalading economic and marketing importance of e-commerce, businesses in the Middle east are considered to have a comparatively low contribution level in e-commerce due to the existence of communal and ecological factors inherent in the region that are affecting individuals using e-commerce. Moreover, the consumers' preferences in the Middle East to deal with a real and physical market reduce the consumer's confidence in e-commerce's transactions (comScore, 2010).

The problem of this research investigated the impact of cultural factors affecting technology growth that have been neglected when considering the use and dissemination of e-commerce in Jordan. The main objective of this study was to show the differences of the cultural dimensions (individualism and collectivism) toward the online purchase intentions in Jordan moderated by the gender factor.

\subsection{The Research Importance}

Research in the domain of online intention purchase has attained a great attention in literature; however, little was given to such topics in Jordan. The Ministry of information and communication technology reported (in its national e-commerce strategy) that despite the acceleration in technology growth in Jordan, the reasons for e-commerce not happening can be expressed in terms of Jordanian culture (National e-commerce strategy, 2007). A report distributed by comScore (2010) showed that the Middle East had 7 percent shares of the worldwide 
Internet audience by December 2009, which was the lowest worldwide. This report also showed that retail online shopping in the Middle East was equal to 0.5 percent, and online business was equal to 0.4 percent by December 2009. These numbers were the lowest among all the regions in the world (comScore, 2010). In this sense, this research provides an excellent opportunity for researchers and practitioners to understand and resolve some of the important issues associated with the dissemination of e-commerce in Jordan.

\subsection{Literature Review}

Hofstede (1980) argued that people carried mental programs that were developed and reinforced through their experience. These mental programs denoted the existence of four underlying value dimensions that could be used to position countries into culture areas. These were: power distance, uncertainty avoidance, individualism and collectivism, and masculinity and femininity. Each of the dimensions represents a different continuum, so that each country could be rated from high to low according to these dimensions. Hofstede's findings (1991) categorized South America and Asia with high-power distance, collectivist and masculine.

\subsubsection{Collectivism}

Collectivism reflects the way people live together (Hofstede, 1980). Chen and West (2008) suggested that collectivism appeared to be a function of social distance. They measured it with respect to parents, friends, and general others. Collectivist societies stress 'we' consciousness including: collective identity, emotional dependence, group solidarity, sharing duties and obligations, need for stable and predetermined friendship, group decision, and participation. Daniels, Radebaugh and Sullivan (2004) stated that the differences between individualism and collectivism could affect the business in several ways. For instance, purchasing decisions in collectivist groups might be more complicated (in comparison with individuals) because of the interrelated roles of family members.

Loch et al. (2003) examined cultural specific inducements and impediment to the use of Internet in the Arab World. Their findings suggested that culture could be a barrier to Internet usage in Arab countries due to the highly social and family oriented nature of the Arab culture. Hofstede's findings (1991) explained that the limited use of Internet was due to the threatening feeling created by how Internet would affect family and community life. It is evident from these findings that there is a link between the collectivist nature and the limited use of Internet.

\subsubsection{Individualism}

Chen and West (2008) concluded that individualism was a multidimensional construct. They assessed independence, competitiveness and uniqueness for individualism. In other words, the individualistic person behaves according to personal attitudes and preferences rather than being influenced by others' opinions or regulations.

Pavlou and Chai (2002) showed that the relationship between attitude and transaction intention was significant for collectivist culture, but insignificant for the individualistic culture. On the other hand some studies suggested that individualism and collectivism do not influence customer loyalty in business to consumer e-commerce. However, individualism and collectivism could explain differences between online and offline shoppers. It is possible that online shopping attracts individualists because the activity does not depend on interaction or social cooperation with others. However, it may be that users of online social networks are more collectivistic, because of apparent benefits to networked interaction (Frost, Goode \& Hart, 2010).

\subsubsection{Gender}

Masculinity and femininity were described as the roles division between sexes to which people in a society put different emphasis on work goals and assertiveness as opposed to personal goals and nurturance (Hofstede, 1980). Gender difference could be explained by gender role theory; i.e. men and women are expected to fulfill different social roles and accordingly face different social pressures. For that reason males and females create differences between groups of individuals within countries. For example, previous studies showed that female participants were more dissatisfied in online shopping than male participants. In addition, men were more likely to buy online than women (Zhang, Mandl \& Wang, 2011). Sangwan, Siguaw and Guan (2009) study showed that gender was significant indicator showing that overall male and female populations had different motivations toward online shopping. Sangwan, Siguaw and Guan (2009) study concluded that male buyers displayed significant higher motivation toward the following points:

- Shop online because of the reliable information they can obtain from online stores. 
- Find online shopping more enjoyable than women.

- Serve as an influence on the online purchases of others.

- Feel a sense of belonging when making purchases from the some online stores as their friends.

- Identify with people with similar interest when shopping online.

- Enjoy knowing people while shopping online.

- Acquire a sense of fulfillment from their online experience.

\subsubsection{Online Purchase Intention}

Intentions to use ICT are employed extensively in information systems research as a dependent variable that reflects the user's choice or as a surrogate for actual use (Weisberg, Te'eni \& Arman, 2001). Consumers' intention to purchase online was proposed by Pavlou and Chai (2002) as the behavioral intention to get involved in online transactions (e.g. products, services, and information buying and selling) with online retailers. To be consist with literature, online purchase intention was employed as a dependent variable in the research model of this study (see figure 1).

\subsection{Hypotheses and the Research Model}

Based on the previous literature, the model of this research was devised (see figure 1). Three hypotheses were formulated. (H1) formulated the effect of gender on online purchase intentions. (H2) formulated the effect of cultural differences (individualist, individualist and collectivist (mixed) and collectivist groups) on online purchase intentions. Finally, (H3) formulated the effect of cultural differences moderated by gender on online purchase intentions.

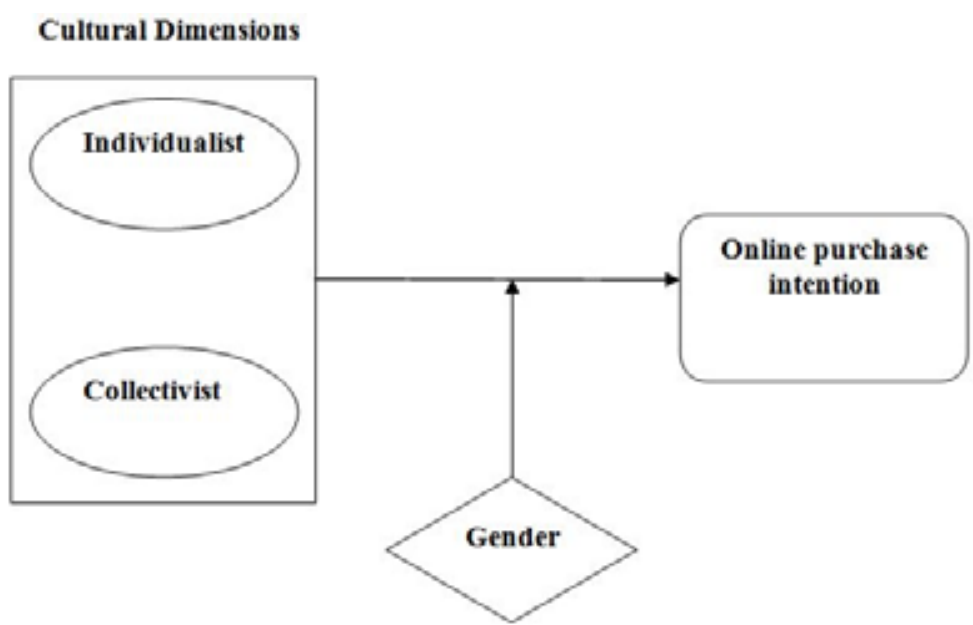

Figure 1. The research model (Authors, 2012)

H1: There is a significant difference between male and female toward online purchase intentions (from the perspective of university students).

H2: Individualist, mixed and collectivist cultural factors make a significant difference in the intention to purchase online (from the perspective of university students).

H3: Individualist, mixed and collectivist gender moderated cultural factors make a significant difference in the intention to purchase online (from the perspective of university students).

\section{Method}

\subsection{Sample Characteristics}

As shown in table 1, 224 respondents were composed of 80 male (35.7\%) and 144 female (64.8\%). Concerning the household annual income, the percentage of those who receive annual salaries between 2000 and 5000 JDs (Jordanian Dinar) is the highest (31.7 percent), followed by those whose annual salary was less than 2000 JDs (28.1 percent). At third place came those whose annual salary was between $5001 \& 10000$ JDs (21.4 percent). Finally the percentage of those receiving annual salaries greater than 10000 JDs was (18.8 percent). 
Table 1. The Main Characteristics of the Sample

\begin{tabular}{lll}
\hline Category & Frequency & Percentage \\
\hline Gender & \multicolumn{2}{l}{} \\
Male & 144 & 35.7 \\
Female & 63.3 \\
\hline Household Annual income & 63 & 28.1 \\
Less than 2000 & 71 & 31.7 \\
2000-5000 & 48 & 21.4 \\
$5001-10000$ & 42 & 18.8 \\
More than 10000 & & \\
\hline On average, how much time do you spend on the Internet per visit? & 46 \\
Less than 1 hour & 109 \\
1-2 Hours & 69 & 20.5 \\
More than 2 hours & & 48.7 \\
\hline On average, how many times do you use the Internet per week? & 6 & 30.8 \\
Never & 85 & 2.7 \\
1-3 Times & 50 & 37.9 \\
4-6 Times & 83 & 22.3 \\
More than 7 times & & 37.1 \\
\hline For how long do you know about shopping online & 35 & 15.6 \\
Less than 6 months & 21 & 9.4 \\
6 months to one year & 168 & 75.0 \\
More than one year & & \\
\hline
\end{tabular}

Regarding the average time spent on the Internet per visit, 20.5 percent of the respondents indicated that they spent less than 1 hour per visit. 48.7 percent of the respondents indicated that they spend between 1-2 hours per visit, and 30.8 percent spent more than 2 hours per visit.

According to the average weekly use of the Internet, 2.7 percent of the respondents indicated that they never used the Internet. While 37.9 percent on average access the Internet 1-3 times weekly, 22.3 percent accessed the Internet 4-6 times weekly. Finally, 37.1 percent of the respondents accessed the Internet more than 7 times per week.

Concerning the respondents' knowledge about online shopping, 75 percent indicated that they knew about shopping online for over one year. This was followed by those who knew about shopping online for less than six months (15.6 percent). Finally 9.4 percent of the respondents indicated that their knowledge of shopping online was between 6 months and one year.

\subsection{Sample Size}

A total of 240 undergraduate business majors, from Al-Balqa Applied University in Jordan, participated in the study. A total of 16 students failed to provide complete information. This sample resulted in a valid sample of 224 participants.

\subsection{Sampling Procedure}

Purposive sampling technique was used in this study. Questionnaires were distributed to students enrolled in undergraduate e-commerce classes. Their participation in the study was entirely voluntary. Furthermore, they received neither course credit nor monetary incentives for their participation. Participants were given surveys that examined a number of issues related to several demographic items, individualism, collectivism and their intention to purchase online.

\subsection{Measures}

The questionnaires were used to collect information including: demographic characteristics, cultural dimensions (individualism, collectivism) and online purchase intention from the selected sample. The collected information is further explained below.

\subsubsection{Individualism}

Respondents' perceptions of individualism were measured using ten items adopted from Frost, Goode and Hart (2010). These items assessed respondents' degree of individualism via five-point Likert-type scale ranging from 1 (strongly disagree) to 5 (strongly agree). The coefficient alpha of this scale was 0.73 . 


\subsubsection{Collectivism}

Respondent perceptions of collectivism were assessed using six items adopted from Frost, Goode and Hart (2010). These items assessed respondents degree of collectivism via five-point Likert-type scale ranging from 1 (strongly disagree) to 5 (strongly agree).The coefficient alpha of this scale was 0.77 .

\subsubsection{Online Purchase Intention}

Intention to purchase was assessed using seven items adopted from Frost, Goode and Hart (2010). Items assessed participant intention to purchase online via 5-point Likert-type scale ranging from 1 (strongly disagree) to 5 (strongly agree). The coefficient alpha was 0.84 .

\subsubsection{Gender (Moderating Variable)}

The gender variable was chosen to have a moderating effect on cultural dimensions (individualism and collectivism). Values associated with gender were1 to indicate male and 2 to indicate female.

\subsection{Factor Analysis}

In table 2 the items related to individualism and collectivism were factor analyzed to reduce their number and the degree of interdependence. Principal factor extraction with the varimax rotation method was used to analyze the responses to the sixteen items associated with individualistic and collectivistic factors. The number of factors retained was determined using Cattell's (1966) screen test. Recommendations varied as to the level at which a factor loading can be considered significant. Hair et al. (1987) reported that factor loadings with an absolute value greater than 0.30 can be considered significant. Stevens (1986) suggested that only loadings with an absolute value greater than 0.40 can be considered significant. In this research, it was decided to adopt Stevens' recommendation. Therefore, Items (8 and 9), which were designed to assess individualism, were excluded from further analyses due to their low loading on both factors. In addition, items (11, 12 and 14), which were designed to assess collectivism, were excluded from further analyses due to their low loading on both factors. The two factors retained accounted for 58 percent of total variance.

Table 2. Factor analysis results of Individualism and collectivism

\begin{tabular}{|c|c|c|c|}
\hline Item No. & Items & Factor 1 (Individualism) & Factor 2 (Collectivism) \\
\hline 1 & I do not like to rely on others & .661 & .030 \\
\hline 2 & What happens to me is my business & .535 & -.041 \\
\hline 3 & I like to behave independently and to have control over things & .645 & -.023 \\
\hline 4 & I try to live independently as much as possible & .538 & -.159 \\
\hline 5 & I depend on myself most of the time and rarely depend on others & .458 & -.035 \\
\hline 6 & $\begin{array}{l}\text { When having a difficult personal problem I prefer that I solve it on my } \\
\text { own rather than follow the advice of others }\end{array}$ & .453 & .040 \\
\hline 7 & My personal identity, independent of others is very important to me & .401 & .048 \\
\hline 8 & Winning is everything for me & .305 & .234 \\
\hline 9 & When another person does better than I do, I get tense & .110 & .313 \\
\hline 10 & I often do "my own thing" & .573 & .106 \\
\hline 11 & To me, pleasure is spending time with others & -.019 & .372 \\
\hline 12 & $\begin{array}{l}\text { It is important to me that I respect decisions made by groups of which I } \\
\text { am a member }\end{array}$ & .125 & .269 \\
\hline 13 & $\begin{array}{l}\text { I feel the importance of staying together with my parents and my } \\
\text { brothers as much as possible }\end{array}$ & -.058 & .759 \\
\hline 14 & Competition is the law of nature & .293 & .172 \\
\hline 15 & $\begin{array}{l}\text { Family members should stick together, no matter what sacrifices are } \\
\text { required. }\end{array}$ & -.082 & .813 \\
\hline 16 & $\begin{array}{l}\text { It is my duty to take care of my family, even when I have to sacrifice } \\
\text { what I want }\end{array}$ & -.134 & .763 \\
\hline
\end{tabular}

\subsection{Cluster Analysis}

Subsequently, factor scores calculated for each respondent from factor scoring coefficients, were submitted for cluster analysis. In this research, hierarchical agglomerative cluster algorithms were used to determine strategic groupings among the sample of this study. Factor submeasure scores for each student were generated for input into the cluster algorithm. The students' sample was first clustered using Ward's method, which seeks to minimize the sum of squared within-cluster distance (Hair et al., 1987). This algorithm was chosen because it has shown to outperform other algorithms in many situations, and it is the most conceptually appealing for the 
identification of strategic groups (Punj \& Stewart, 1983). A three-cluster solution was chosen based on analysis of a plot of the number of clusters versus the standardized distance coefficient, because this number of clusters was the smallest that adequately differentiated the students as shown in table 3.

Table 3. Cluster analysis results of Individualism and collectivism

\begin{tabular}{|c|c|c|c|c|c|c|}
\hline Factor dimension & $\begin{array}{l}\text { Collectivist } \\
\text { group (1) } \\
\mathrm{n}=77\end{array}$ & $\begin{array}{l}\text { Individualist and Collectivist } \\
\text { (Mixed group) (2) } \\
\mathrm{n}=98\end{array}$ & $\begin{array}{l}\text { Individualist group (3) } \\
\mathrm{n}=49\end{array}$ & $\mathrm{~F}$ & $\mathrm{P}$ & Scheffe \\
\hline Factor of individualism & -1.080 & .585 & .562 & 182.868 & .000 & $(1)-(2),(1)-(3)$ \\
\hline Factor of Collectivism & .2458 & .401 & -1.266 & 81.452 & .000 & $(1)-(3),(2)-(3)$ \\
\hline
\end{tabular}

Based on the one way ANOVA test, three groups were identified according to the individualist and collectivist cultural dimensions. These groups were: Collectivist group (1), Individualist and Collectivist (mixed group) (2), and Individualist group (3). The study indicated that there were differences between groups ( 2 \& 3 ) with group (1) related to the factor of individualism. Furthermore, the study showed that there were differences between groups ( $1 \& 2$ ) with group (3) related to the factor of collectivism. Moreover, the analysis showed group (2) as an overlapping of group (1) and group (3).

\subsection{Data Analysis}

Descriptive statistics (frequency, means, standard deviations, reliability, and inter correlations) were computed. The reliability of the scales for the constructs in this study was tested. The reliability of each construct in this study achieved an acceptable Cronbach alpha of over 0.7 (Nunnally, 1978). To achieve the objectives of this research, Univariate Analysis of variance were used; two independent sample tests were used to test the first and second hypotheses. Hierarchical regression was used to test the third hypothesis.

\section{Results}

\subsection{Descriptive Analysis}

Descriptive statistics, coefficient alpha reliabilities and correlations for the variables used in the present study were shown in table 4 . All scale reliabilities exceeded the 0.70 value recommended by Nunnally (1978).

The results indicated that there was a significant and positive correlations between the individualism and intention to purchase online variables $(\mathrm{r}=.225)$.

Table 4. Means, standard deviations, reliability coefficients, and intercorrelations of the study variables

\begin{tabular}{llllll}
\hline Variables & Mean & Std deviation & Alpha & $\mathbf{1}$ & $\mathbf{2}$ \\
\hline Collectivism & 4.293 & .560 & .766 & & \\
Individualism & 4.004 & .550 & .765 & -.018 & \\
Intention to purchase & 2.824 & .757 & .84 & -.126 & $.225^{*}$ \\
\hline
\end{tabular}

Note: Sig $<0.05$.

\subsection{Hypotheses Testing}

Hypotheses testing were represented based on the results of tables 5 and 6.

Table 5. Summary of Analysis of variance

\begin{tabular}{lllll}
\hline Source & df & MS & F & Sig. \\
\hline Gender & 1 & 10.672 & $21.594^{*}$ & .000 \\
Group & 2 & 4.532 & $9.171^{*}$ & .000 \\
Gender X Group & 2 & 1.549 & $3.135^{*}$ & .045 \\
Error & 218 & .494 & & \\
\hline
\end{tabular}

Note: Sig $<0.05$.

H1: There is a significant difference between male and female toward online purchase intentions (from the perspective of university students).

Table 5 presented the analysis of variance statistical results. Gender appeared to have a significant impact on intention to purchase online $(\mathrm{F}=21.594, \mathrm{P}<0.05)$. Also, the results from the mean scores for the intention to 
purchase online showed that males preferred to purchase online (mean $=3.125$, Std $=.081$ ) more than females (mean $=2.652$, Std $=.061$ ); Therefore, the first hypothesis (H1) was supported.

H2: Individualist, mixed and collectivist cultural factors make a significant difference in the intention to purchase online (from the perspective of university students).

The two way ANOVA results in table 5 showed that there was a statistical significant difference in the intention to purchase online according to individualist, mixed and collectivist cultural factors $(\mathrm{F}=9.171, \mathrm{P}<.05)$. Therefore, the second hypothesis (H2) was supported. However, the Sheffe test demonstrated that collectivist group (mean $=2.56$ ) had less intention to purchase online in comparison with individualist (mean $=2.94$ ) and mixed groups $($ mean $=2.98)$.

H3 Individualist, mixed and collectivist gender moderated cultural factors make a significant difference in the intention to purchase online (from the perspective of university students).

Table 6. Interaction mean scores

\begin{tabular}{cccc}
\hline Variable & Collectivist Group & Mixed Group & Individualist Group \\
\hline Male & 2.722 & 3.168 & 3.484 \\
Female & 2.464 & 2.875 & 2.618 \\
\hline
\end{tabular}

Research hypothesis (H3) related to whether there was an interaction effect between gender and individualist, mixed and collectivist groups on intention to purchase online. The two-way interaction between gender and individualist, mixed and collectivist groups was significant regarding intention to purchase online $(\mathrm{F}=3.135, \mathrm{P}$ $<.05$ ). Therefore, the third hypothesis (H3) was supported.

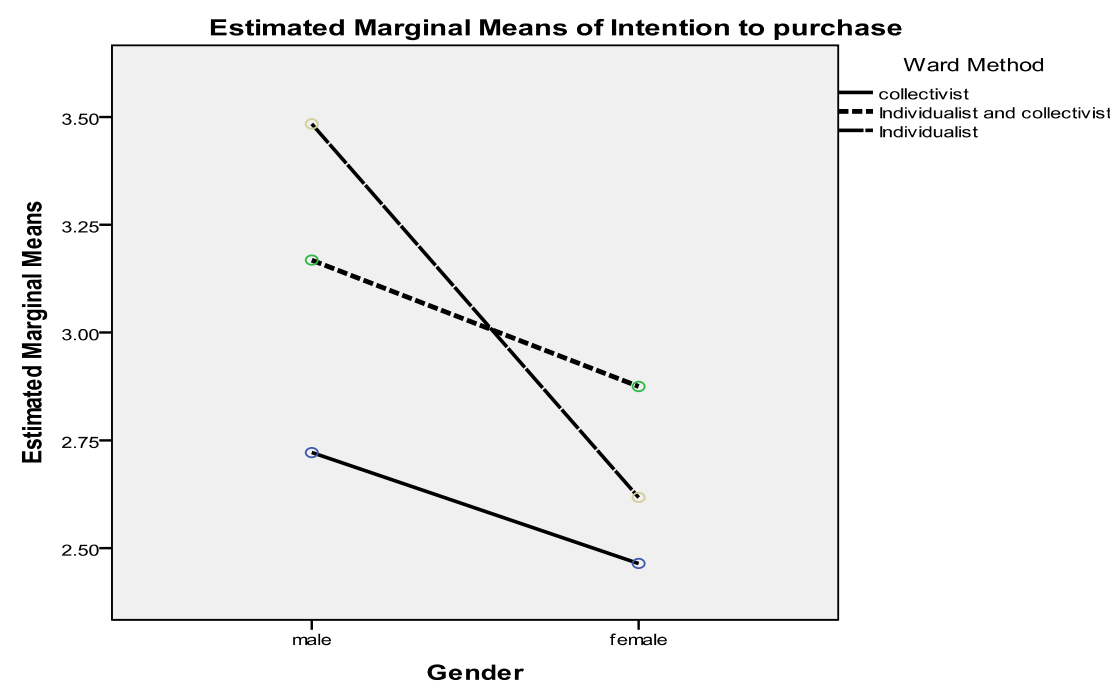

Figure 2. Means plot of intention to purchase online based on gender, individualist and collectivist groups

In figure 2 and table 6, which represents the mean of intention to purchase online for each combination of gender, collectivist, mixed, and individualist groups, it was observed that the two lines representing collectivist and mixed groups are roughly parallel. On the other hand, there was an intersection between the lines representing the individualist and mixed groups indicating that there was an interaction between these two groups.

\section{Conclusions, Limitations and Future Research}

The main objective of this study was to show the differences of the cultural dimensions toward the online purchase intentions in Jordan moderated by the gender factor.

The study found a significant difference in intention to purchase online based on gender. The results showed that males preferred online purchase more than females. This result was in accordance with Hui and Wan (2007) study which justified this behavior to the inability of female consumers to enjoy online shopping experience. According to a home survey conducted by the department of statistics in Jordan (2010) about information technology use, it was found that the use of e-commerce services among males was higher than females. The 
study found significant differences related to individualist, mixed and collectivist groups. These results could be explained in terms of the psychological concepts of individualism and collectivism that direct the personality regardless of the gender. The results of the study found that collectivist groups had the lowest intention to purchase online. Despite Jordan being considered a collectivist culture (Hofstede, 2011), students preferred the response that mixed both collectivistic and individualistic orientations for purchasing online. Furthermore, the study indicated that there was a significant interaction effect between gender and collectivist, mixed and individualist groups on the intention to purchase online. Initially, the gender variable had the same effect on the collectivistic and mixed groups toward the intention to purchase online. Whereas, there was an interaction effect between the individualistic and mixed groups. It was noticed that the individualistic group males had a higher intention to purchase online than mixed group males. On the other hand, individualistic group females had a lower intention to purchase online than mixed group females. This concluded that male individualistic group scored the highest intention toward purchasing online. Based on (authors') experience and observations, such a phenomenon could be explained by the fact that Jordanian society supports the decisions generally made by male individuals. This eventually would empower male individuals and may explain their increasing intention to online purchasing

The main limitation of this study was related to the difficulty of reaching online customers other than students which limited the generalizability of results from this study. Another limitation of this study was undertaken in a developing country where the IT infrastructure and knowledge is still evolving.

A detailed and more comprehensive research related to online shopping behavior and cross cultural studies in the Middle East in general and Jordan in specific needs to be conducted in the future.

\section{References}

Cattell, R. B. (1966). The scree test for the number of factors. Multivariate Behavioral Research, 1, 245-276. http://dx.doi.org/10.1207/s15327906mbr0102_10

Chen, F. F., \& West, S. G. (2008). Measuring Individualism and Collectivism: The Importance of Considering Differential Components, Reference Groups, and Measurement Invariance. Journal of Research in Personality, 42, 259-294. http://dx.doi.org/10.1016/j.jrp.2007.05.006

ComScore Inc. (2010). Data Passport, First Half. Retrieved from http://www.comscore.com/Press_Events/Presentations_Whitepapers/2010/The_comScore_Data_Passport__First_Half_2010

Daniels, J. D., Radebaugh, L. H., \& Sullivan, D. P. (2004). International Business Environments and Operations. New Jersey: Pearson Prentice Hall.

Department of statistics in Jordan. (2010). Retrieved from http://www.dos.gov.jo/dos_home_e/main/index.htm

Frost, D., Goode, S., \& Hart, D. (2010). Individualist and Collectivist Factors Affecting Online Repurchase Intentions. Internet Research, 20(1), 6-28. http://dx.doi.org/10.1108/10662241011020815

Gong, W. (2009). National culture and global diffusion of business-to-consumer e-commerce. Cross Cultural Management: An International Journal, 16(1), 83-101. http://dx.doi.org/10.1108/13527600910930059

Hair, J. F., Anderson, R. E., \& Tatham, R. L. (1987). Multivariate Data Analysis (p. 449). New York: MacMillan.

Henari, T. F., \& Mahboob, R. (2008). E-commerce in Bahrain: the non-technical limitations, Education, Business and Society. Contemporary Middle Eastern Issues, 1(3), 213-220. http://dx.doi.org/10.1108/17537980810909832

Hofstede, G. H. (1980). Culture Consequences: International Differences in Work-related Values. London: Sage Publications.

Hofstede, G. H. (1991). Cultures and Organizations: Software of the Mind: Intercultural Cooperation and Its Importance for Survival. New York: McGraw-Hill International.

Hofstede, G. H. (2011). GEERT HOFSTEDE -What about Jordan? Retrieved from http://geert-hofstede.com/jordan.html

Javalgi, R. G., Wickramasinghe, N., Scherer, R., \& Sharma, S. (2005). An assessment and strategic guidelines for developing e-commerce in the Asia-Pacific Region. International Journal of Management, 22(4), 523-32.

$\begin{array}{ccccc}\begin{array}{c}\text { National } \\ \text { http://www.thieswittig.eu/docs/MPC_Strategies/Jordan/Jordan_eCommerceStrategy.pdf }\end{array} & \text { E-commerce } & \text { from }\end{array}$ 
Nunnally, J. (1978). Psychometric Theory. New York: McGraw-Hill.

Pavlou, P. A., \& Chai, L. (2002). What Drives Electronic Commerce across Cultures? A Cross-Cultural Empirical Investigation of the Theory of Planned Behavior. Journal of Electronic Commerce Research, 3(4), 240-253.

Punj, G., \& Stewart, D. W. (1983). Cluster Analysis in Marketing Research: Review and Suggestions for Application. Journal of Marketing Research, 20(2), 134-148. http://dx.doi.org/10.2307/3151680

Sangwan, S., Siguaw, J. A., \& Guan, C. (2009). A Comparative Study of Motivational Differences for Online Shopping. The Database for Advances in Information Systems, 40(4), 28-42. http://dx.doi.org/10.1145/1644953.1644957

Stevens, J. (1986). Applied multivariate statistics for the social sciences. Hillsdale, NJ: Lawrence Erlbaum.

Weisberg, J., Te'eni, D., \& Arman, L. (2011). Past purchase and Intention to Purchase in E-commerce: The mediation of Social Presence and Trust. Internet Research, 21(1), 82-96. http://dx.doi.org/10.1108/10662241111104893

Zhang, J., Mandl, H., \& Wang, E. (2011). The Effect of Vertical-Horizontal Individualism-Collectivism on Acculturation and the Moderating Role of Gender. International Journal of Intercultural Relations, 35, 124-134. http://dx.doi.org/10.1016/j.ijintrel.2010.09.004 